\title{
Prediction on Peak Values of Carbon Dioxide Emissions from the Chinese Transportation Industry Based on the SVR Model and Scenario Analysis
}

\author{
Changzheng Zhu (iD, Meng Wang, and Wenbo Du \\ School of Modern Post, Xi'an University of Posts and Telecommunications, Xian 710061, China \\ Correspondence should be addressed to Changzheng Zhu; zhuchangzheng@xupt.edu.cn
}

Received 25 June 2020; Revised 28 August 2020; Accepted 25 September 2020; Published 23 October 2020

Academic Editor: Petr Dolezel

Copyright (c) 2020 Changzheng Zhu et al. This is an open access article distributed under the Creative Commons Attribution License, which permits unrestricted use, distribution, and reproduction in any medium, provided the original work is properly cited.

\begin{abstract}
As the largest emitter of greenhouse gases in the world, the peak values of Chinese $\mathrm{CO}_{2}$ emissions have attracted extensive attention at home and abroad. The carbon dioxide emissions of the Chinese transportation industry, accounting for $9.5 \%$ of total carbon dioxide emissions, is one of the high-emission industries, and its total carbon dioxide emissions continue to rise. Therefore, the accurate prediction of the peak values of carbon dioxide emissions from the Chinese transportation industry is helpful for China to formulate a reasonable policy of carbon dioxide emissions control. This paper, firstly, selects six major factors affecting the carbon dioxide emissions of the Chinese transportation industry. They are the Gross Domestic Product (GDP), population, urbanization rate, energy consumption structure, energy intensity, and industrial structure. Then, it builds a prediction model of carbon dioxide emissions based on Support Vector Regression (SVR). Finally, it analyses the sensitivity of each factor. The predicted results show that, under the baseline scenario, they will reach a peak of 1365.71 million tons in 2040; under the lowcarbon scenario, the carbon dioxide emissions of Chinese transportation will peak at 1115.43 million tons in 2036; and in the highcarbon scenario, the peak value will occur in 2046 and the carbon dioxide emissions will be 1738.18 million tons. In order to promote the early peak of carbon dioxide emissions from the transportation industry, it is, firstly, necessary to change the mode of economic growth and appropriately reduce the speed of economic development. Secondly, the energy intensity of the transportation industry is reduced and the utilization rate of clean energy is improved. Thirdly, the industrial structure is optimized. Fourthly, the carbon dioxide emissions of the transportation industry caused by the increased urbanization rate are reasonably controlled.
\end{abstract}

\section{Introduction}

With the development of the world economy, the situation of carbon dioxide emissions control is becoming increasingly serious. In November 2019, the United Nations Environment Programme (UNEP) released the Emissions Gap Report, which pointed out that human efforts to control carbon dioxide emissions have been too weak in the recent ten years, and the global carbon dioxide emissions have been always on the rise, leading to broader and more destructive climate influences. In December 2019, the 25th conference of the parties to the United Nations convention on climate change was held in Spain, and the United Nations secretary-general Antonio Guterres has called on all countries to adopt more effective measures to control the growth of carbon dioxide emissions. According to the report from the Netherlands Environmental Assessment Agency, China surpassed the United States as the world's largest country of $\mathrm{CO}_{2}$ emissions in 2006. Also, according to the International Energy Agency (IEA) data, Chinese $\mathrm{CO}_{2}$ emissions reached 9.30 billion tons in 2017, accounting for $28.33 \%$ of the world's total volumes. Among them, the $\mathrm{CO}_{2}$ emissions of transportation industry accounted for $9.5 \%$ of Chinese total volumes, making it a major carbon emitter in the national economy. 
However, compared with other industries, the Chinese transportation industry is not ideal enough in carbon dioxide emissions control because of its multiple and complicated emission sources. Therefore, the prediction of the future peak values of carbon dioxide emissions in the Chinese transportation industry is helpful for the government administration departments to realize the grim situation of carbon dioxide emissions control in the transportation sector, so as to speed up the formulation of more stringent policies for carbon dioxide emissions control.

At present, the relevant research studies of domestic and foreign scholars mainly focus on the influencing factors and prediction of carbon dioxide emissions in the transportation industry. In terms of influencing factors, the research results of most scholars show that the economic level [1-5], population [2, 3, 5, 6], energy intensity $[2,3,7,8]$, energy consumption structure [4-7], urbanization rate [5], and industrial structure [9-11] are the main factors affecting the carbon dioxide emissions of the transportation industry. There are also a few scholars who believe that transportation demand [4], the level of transportation development [6], the added value of the transportation industry [7], transportation intensity [8], the market concentration level [12], energy efficiency [13], average driving distance, and the number of motor vehicles [14] are also important factors affecting carbon dioxide emissions.

As for the prediction of carbon dioxide emissions, the most widely used prediction models include the IPAT model [15], STIRPAT model [16], scenario analysis method $[17,18]$, and regression analysis method [19]. In the early 1970s, Ehrlich et al. established the famous IPAT equation [20] to study the impact of population on environmental change. However, IPAT equation has a certain limitation, which is to analyze the influence of a changed factor on environmental change on the premise of keeping other factors unchanged, so as to obtain the result of equal proportional influence on dependent variables. In order to solve this limitation, Dietz et al. proposed the random model of environmental impact, namely, the STIRPAT model [21]. However, the STIRPAT model mostly specifies different models by simply adding or deleting variables [22]. Even with the improved STIRPAT model, most of the influencing factors are randomly selected to conform to the multiplication rules of the model. Without necessary theoretical support, the credibility of the empirical results will decline [23]. The scenario analysis method is often used in combination with other methods in practical research centers because it only establishes a set of framework and analysis of environmental impact in each scenario must also rely on other more specific methods. As for the regression analysis method, due to the strict assumption of its equation, it is necessary to know all explanatory variables that cause the change of dependent variables; otherwise, it is easy to have problems such as false regression, resulting in the failure of the hypothesis test. But, there are many influencial factors of carbon dioxide emissions, so it is relatively difficult in this choice.
In the recent years, machine learning methods have been widely applied to the prediction of carbon dioxide emissions. Chen et al. used the artificial neural network (ANN) to predict $\mathrm{CO}_{2}$ emissions and estimated $\mathrm{CO}_{2}$ emissions from global reservoirs [24]. However, due to the very slow convergence speed of the neural network algorithm, it is easy to fall into the local minimum [25]. Support vector machine (SVM) is a new machine learning algorithm based on statistical learning theory. Because of its good learning performance, it has been used for classification and regression problems. This solves the defects of the prior method and becomes an effective method of carbon emission prediction [26]. Chen et al. established a prediction model for regional carbon emissions based on support vector regression machine to predict the carbon emissions of Beijing's transportation industry [27]. Song et al. predicted Chinese carbon emissions from 2010 to 2015 based on taking the data of Chinese carbon emissions and influencing factors from 1980 to 2009 as samples and combining with the $12^{\text {th }}$ Five-Year Plan [28]. Xue et al. analyzed the advantages of support vector regression machine model in carbon emission prediction and built a prediction model of carbon emissions based on this. By using the data of carbon emissions in Hebei Province from 1990 to 2015 and its influencing factors, we predicted the carbon emissions of Hebei Province from 2016 to 2015 and provided suggestions for carbon emissions reduction [29].

This paper combines the Support Vector Regression (SVR) machine model and the scenario analysis method, uses their advantages to solve the problem of small sample and nonlinearity to forecast the peak value of the Chinese transportation industry in the three scenarios of high-carbon scenario, benchmark scenario, and low-carbon scenario, and provides references for the government making carbon emission control policies.

\section{Establishment of the Prediction Model and Selection of Influencing Factors}

\subsection{Model Establishment}

2.1.1. Selection of the Prediction Model. The carbon dioxide emissions of transportation industry are often affected by economic, social, and other factors. Through comparative analyses, this paper selects the SVR model as the prediction model for carbon dioxide emissions of transportation industry. Firstly, the main idea of SVR is to maximize classification boundaries and adapt to various nonlinear situations by selecting a kernel function, which is more suitable for nonlinear data regression prediction than the traditional prediction model. Secondly, the SVR model can realize efficient transformation from training the sample set to the prediction sample set through the small sample learning method, which can solve the problem of small sample data. Finally, in the perspective of obtaining the global optimal solution, the SVR model will be transformed into a convex optimization problem in the final calculation to ensure the global optimal result. Therefore, the SVR model is selected for carbon dioxide emissions' prediction in this paper [30]. 
2.1.2. Specific Steps of Predictions. SVR is a prediction method based on structural risk minimization, which can comprehensively consider the fitness and complexity of training samples and achieve the optimal effect in function approximation, regression prediction, and other aspects. In this paper, the nonlinear SVR model is selected for predictions.

The data of carbon dioxide emissions were obtained from transportation industry and related influencing factors for 45 years from 1973 to 2017, and the SVR model is built for carbon dioxide emissions of transportation industry; the specific steps are as follows:

Step 1. Independent variables and dependent variables in the sample data are normalized, so that all data are between $[0,1]$. After normalization, all indexes are in the same order of magnitude, which is convenient for comprehensive comparisons and improves calculation accuracy. The normalization method is shown as follows:

$$
\begin{aligned}
& x_{i}^{*}=\frac{x_{i}-x_{\min }}{x_{\max }-x_{\min }}, \\
& y_{i}^{*}=\frac{y_{i}-y_{\min }}{y_{\max }-y_{\min }} .
\end{aligned}
$$

In the formulas, $x_{i}, y_{i}$ are elements of the data to be normalized; $x_{\max }, y_{\max }$ are the largest elements in data matrix; $x_{\min }, y_{\min }$ are the smallest elements in data matrix; and $x_{i}^{*}, y_{i}^{*}$ are normalized data.

Step 2. Kernel function and parameter selection

Firstly, the selection of the SVM kernel function plays a crucial role in the performance of SVM. By means of the LIBSVM toolbox, this paper selects the radial basis kernel function $K\left(x_{i}, x\right)=\left(\Phi\left(x_{i}\right) \cdot \Phi(x)\right)=\exp (-\gamma$ $\left.\left\|x_{i}-x\right\|^{2}\right)$ as the kernel function of the $\varepsilon$-SVR model after systematic analysis of the selected data of each year. Secondly, after LIBSVM adopts the kernel function, the model parameters that are need to be determined are only penalty factor $c$ and kernel function parameter $g$. The initial value $\varepsilon$ is set, the values of parameters $c$ and $g$ are determined with the grid algorithm, and finally, the optimal parameters are obtained by comparisons.

Step 3. The prediction model is established, simulation is carried out for sample set data by MATLAB, and the deviation degree between the prediction data of the training sample and the actual data is compared. The learning and promotion ability of the SVR model are judged by fitting the prediction index, namely, Mean Squared Error (MSE). At the same time, the data of the test set are substituted into, and their mean square error (MSE) is verified. If it is in line with the expectation, the following prediction analysis is carried out. Otherwise, we go back for continuing learning.

Step 4. The predicted values of influencing factors of transportation carbon dioxide emissions are normalized, they are substituted into the established prediction model, the results are output, and the inverse normalization is carried out, so as to obtain the required prediction data of carbon dioxide emissions under different scenarios. Inverse normalization is an inverse process of data normalization. The formula is

$$
y_{i}=y_{i}\left(y_{\max }-y_{\min }\right)+y_{\min }
$$

2.2. Selection of Influencing Factors for Carbon Dioxide Emissions. From the abovementioned literature studies, the factors affecting carbon dioxide emissions of Chinese transportation industry mainly include the GDP, population, urbanization rate, transportation development level, transportation energy intensity, energy consumption structure, and industrial structure. The level of traffic development is a comprehensive indicator, and there exist some differences in how to measure it quantitatively; therefore, this paper excludes this indicator. In addition, the classical regression analysis requires the independent variables to be linearly independent while the support vector machine (SVM) model does not require the independent variables to be linearly independent. Therefore, when using the regression model of SVM to predict the peak of carbon dioxide emissions, this paper selects six indicators of GDP, population, urbanization rate, energy consumption structure, energy intensity, and industrial structure as the main factors affecting the carbon dioxide emissions of the transportation industry. Among them, the energy consumption structure refers to the proportion of fossil energy consumptions of the transportation industry in the total energy consumptions, and the industrial scale refers to the proportion of the secondary industry in GDP.

2.3. Setting of the Predicted Scenario. If China wants to make the policies of carbon dioxide emissions control suitable for its national conditions, it is crucial to accurately predict the peak values of carbon dioxide emissions. Since the peak values of carbon dioxide emissions vary under different scenarios, scenario analysis is needed to predict the peak of carbon dioxide emissions in the Chinese transportation industry. Different scenarios refer to the different change rates of the six factors in the future. In this paper, three scenarios are set up, namely, the benchmark scenario, the high-carbon scenario, and the low-carbon scenario. They are specified as follows: (1) the baseline scenario: in this scenario, the future change rates of the six influencing factors continue the previous change trends, and the change range is moderate; (2) the highcarbon scenario: in this scenario, the future changes of the six influencing factors will lead to higher carbon dioxide emissions than those under the benchmark scenario, such as the faster growth of GDP and urbanization rate; (3) the low-carbon scenario: in this scenario, the future changes of the six influencing factors contribute to lower carbon dioxide emissions than those under the baseline scenario. The detailed parameter setting of each scenario is given in the following. 


\section{Data Source and Preprocessing}

\subsection{Data Sources}

3.1.1. Independent Variable. In this paper, the population and urbanization rate come from World Development Indicators (WDI), and the energy consumption structure comes from the International Energy Agency (IEA). Here is the percentage of fossil energy consumption in transportation industry accounting for the total energy consumptions, and the rest of the data come from the comprehensive and publicly published Chinese Statistical Yearbook of past years. The sample interval is from 1973 to 2017.

The energy intensity of transportation industry is expressed by the total energy consumption of the unit conversion turnover, which can measure the comprehensive energy utilization efficiency of the industry. Total energy consumption in the Chinese transportation sector comes from the website of IEA. When calculating conversion turnover, passenger turnover is multiplied by the passengercargo conversion coefficient and added to cargo turnover to get the total conversion turnover. The turnover coefficients of passenger-cargo conversion for the four modes of transportation are shown in Table 1. The data of turnover of each transportation mode are derived from the statistical yearbook of China over the years. The converted turnover of the Chinese transportation industry is shown in Table 2. Finally, the energy intensity of the Chinese transportation industry over the years can be obtained by dividing the total energy consumption by the conversion turnover.

The final analyses of the factors from 1973 to 2017 are shown in Table 3.

\subsubsection{Carbon Dioxide Emissions Calculation Method.} Carbon emissions refer to the general term of greenhouse gas emissions, mainly including carbon dioxide, nitrous oxide, and methane. Among them, $\mathrm{CO}_{2}$ is the major greenhouse gas that induces the global warming. Since there are no comprehensive statistics for global carbon dioxide emissions at present, most scholars adopt the method of carbon dioxide emissions coefficient, proposed by the Intergovernmental Panel on Climate Change (IPCC) [31], to calculate carbon dioxide emissions through the data of energy consumptions. This method, proposed by the IPCC in 1996, states that the total amount of carbon dioxide emissions is equal to the product of the activity data affecting carbon dioxide emissions and the carbon dioxide emissions coefficient per unit. Therefore, the specific expression formula of carbon dioxide emissions adopted in this paper is as follows:

$$
C=\sum_{i} E_{i} \times \delta_{i}=\sum_{i} E_{i} \times V_{i} \times R_{i} \times F_{i} \times \frac{44}{12},
$$

where $C$ represents $\mathrm{CO}_{2}$ emissions from transportation industry; $i$ indicates categories of fossil fuels, that is, the IEA database divides the fuels consumed by transportation into five categories of coal, petroleum products, biomass energy,
TABle 1: Conversion factor of traffic turnover in China.

\begin{tabular}{lcccc}
\hline Mode of transportation & Road & Railway & Waterway & Airport \\
\hline $\begin{array}{l}\text { Conversion factor } \\
\left(\mathrm{t} \cdot \mathrm{km} \cdot(\mathrm{p} \cdot \mathrm{km})^{-1}\right)\end{array}$ & $1 / 10$ & 1 & 1 & $1 / 13$ \\
\hline
\end{tabular}

Note: $\mathrm{t} \cdot \mathrm{km}=$ Tonne $\cdot$ kilometer; $\mathrm{p} \cdot \mathrm{km}=$ people $\cdot$ kilometer.

TABle 2: Converted turnover of the Chinese transportation industry from 1973 to 2017.

\begin{tabular}{|c|c|}
\hline Year & Conversion turnover $\left(10^{8} \mathrm{t} \cdot \mathrm{km}\right)$ \\
\hline 1973 & 7314.38 \\
\hline 1974 & 7362.46 \\
\hline 1975 & 8378.88 \\
\hline 1976 & 7996.79 \\
\hline 1977 & 9136.04 \\
\hline 1978 & 11077.59 \\
\hline 1979 & 12778.34 \\
\hline 1980 & 13614.13 \\
\hline 1981 & 13840.80 \\
\hline 1982 & 14869.30 \\
\hline 1983 & 16099.98 \\
\hline 1984 & 18033.79 \\
\hline 1985 & 20882.01 \\
\hline 1986 & 23085.12 \\
\hline 1987 & 25449.03 \\
\hline 1988 & 27490.33 \\
\hline 1989 & 29016.77 \\
\hline 1990 & 29264.84 \\
\hline 1991 & 31302.15 \\
\hline 1992 & 32918.72 \\
\hline 1993 & 34733.32 \\
\hline 1994 & 37719.44 \\
\hline 1995 & 40139.12 \\
\hline 1996 & 40646.43 \\
\hline 1997 & 42738.74 \\
\hline 1998 & 42638.28 \\
\hline 1999 & 45496.81 \\
\hline 2000 & 49693.86 \\
\hline 2001 & 53371.48 \\
\hline 2002 & 56615.42 \\
\hline 2003 & 59577.33 \\
\hline 2004 & 76235.64 \\
\hline 2005 & 87474.71 \\
\hline 2006 & 96730.72 \\
\hline 2007 & 110078.42 \\
\hline 2008 & 119607.96 \\
\hline 2009 & 131692.00 \\
\hline 2010 & 152484.47 \\
\hline 2011 & 171035.03 \\
\hline 2012 & 185927.63 \\
\hline 2013 & 180238.12 \\
\hline 2014 & 194570.60 \\
\hline 2015 & 192023.74 \\
\hline 2016 & 200948.59 \\
\hline 2017 & 212615.34 \\
\hline
\end{tabular}

natural gas, and electricity; $E_{i}$ represents the energy consumption of fossil fuel $i$; $\delta_{i}$ is the $\mathrm{CO}_{2}$ emissions coefficient of carbon energy $i$; $V_{i}$ is the average low calorific value of energy $i ; F_{i}$ is the carbon dioxide emissions coefficient of energy $i ; R_{i}$ is the carbon oxidation factor, that is, the carbon 
Table 3: Data of traffic carbon dioxide emissions and their influencing factors.

\begin{tabular}{|c|c|c|c|c|c|c|}
\hline Year & GDP $\left(10^{9}\right.$ yuan $)$ & $\begin{array}{c}\text { Population } \\
\text { (million people) }\end{array}$ & Urbanization rate (\%) & $\begin{array}{c}\text { Energy consumption } \\
\text { structure (\%) }\end{array}$ & $\begin{array}{c}\text { Energy intensity } \\
\left(\mathrm{t} / 10^{6} \mathrm{t} \cdot \mathrm{km}\right)\end{array}$ & $\begin{array}{l}\text { The proportion of the } \\
\text { secondary industry (\%) }\end{array}$ \\
\hline 1973 & 2756.20 & 881.94 & 17.18 & 100 & 3.12 & 42.80 \\
\hline 1974 & 2764.13 & 900.35 & 17.29 & 100 & 3.49 & 42.40 \\
\hline 1975 & 2733.36 & 916.40 & 17.40 & 100 & 3.24 & 45.40 \\
\hline 1976 & 2731.29 & 930.69 & 17.46 & 100 & 3.57 & 45.00 \\
\hline 1977 & 2760.39 & 943.46 & 17.52 & 100 & 3.44 & 46.70 \\
\hline 1978 & 2797.23 & 956.17 & 17.90 & 100 & 2.84 & 47.70 \\
\hline 1979 & 2897.74 & 969.01 & 18.62 & 100 & 2.57 & 47.00 \\
\hline 1980 & 3007.38 & 981.24 & 19.36 & 100 & 2.20 & 48.10 \\
\hline 1981 & 3078.63 & 993.89 & 20.12 & 100 & 2.17 & 46.00 \\
\hline 1982 & 3145.57 & 1008.63 & 20.90 & 100 & 2.11 & 44.60 \\
\hline 1983 & 3109.54 & 1023.31 & 21.55 & 100 & 2.13 & 44.20 \\
\hline 1984 & 3263.05 & 1036.83 & 22.20 & 100 & 1.98 & 42.90 \\
\hline 1985 & 3597.14 & 1051.04 & 22.87 & 100 & 1.78 & 42.70 \\
\hline 1986 & 3766.86 & 1066.79 & 23.56 & 100 & 1.79 & 43.50 \\
\hline 1987 & 3956.78 & 1084.04 & 24.26 & 100 & 1.74 & 43.30 \\
\hline 1988 & 4436.76 & 1101.63 & 24.97 & 100 & 1.66 & 43.50 \\
\hline 1989 & 4818.71 & 1118.65 & 25.70 & 100 & 1.67 & 42.50 \\
\hline 1990 & 5094.93 & 1135.19 & 26.44 & 96.77 & 1.51 & 41.00 \\
\hline 1991 & 5435.16 & 1150.78 & 27.31 & 97.06 & 1.55 & 41.50 \\
\hline 1992 & 5881.59 & 1164.97 & 28.20 & 97.30 & 1.61 & 43.10 \\
\hline 1993 & 6773.79 & 1178.44 & 29.10 & 97.62 & 1.73 & 46.20 \\
\hline 1994 & 8173.02 & 1191.84 & 30.02 & 97.50 & 1.52 & 46.20 \\
\hline 1995 & 9286.06 & 1204.86 & 30.96 & 97.67 & 1.53 & 46.80 \\
\hline 1996 & 9892.30 & 1217.55 & 31.92 & 98.25 & 2.00 & 47.10 \\
\hline 1997 & 10055.60 & 1230.08 & 32.88 & 98.00 & 1.67 & 47.10 \\
\hline 1998 & 9969.33 & 1241.94 & 33.87 & 97.92 & 1.61 & 45.80 \\
\hline 1999 & 9839.91 & 1252.74 & 34.87 & 98.15 & 1.69 & 45.40 \\
\hline 2000 & 10041.96 & 1262.65 & 35.88 & 98.81 & 2.41 & 45.50 \\
\hline 2001 & 10250.91 & 1271.85 & 37.09 & 98.82 & 2.27 & 44.80 \\
\hline 2002 & 10315.81 & 1280.40 & 38.43 & 98.91 & 2.32 & 44.50 \\
\hline 2003 & 10588.00 & 1288.40 & 39.78 & 97.17 & 2.54 & 45.60 \\
\hline 2004 & 11325.49 & 1296.08 & 41.14 & 97.60 & 2.34 & 45.90 \\
\hline 2005 & 11767.03 & 1303.72 & 42.52 & 97.01 & 2.19 & 47.00 \\
\hline 2006 & 12231.34 & 1311.02 & 43.87 & 95.95 & 2.18 & 47.60 \\
\hline 2007 & 13182.79 & 1317.89 & 45.20 & 96.23 & 2.06 & 46.90 \\
\hline 2008 & 14204.05 & 1324.66 & 46.54 & 94.25 & 2.08 & 47.00 \\
\hline 2009 & 14174.12 & 1331.26 & 47.88 & 92.74 & 1.94 & 46.00 \\
\hline 2010 & 15154.41 & 1337.71 & 49.23 & 92.89 & 1.84 & 46.50 \\
\hline 2011 & 16370.89 & 1344.13 & 50.51 & 92.13 & 1.80 & 46.50 \\
\hline 2012 & 16746.90 & 1350.70 & 51.77 & 92.02 & 1.83 & 45.40 \\
\hline 2013 & 17103.82 & 1357.38 & 53.01 & 91.83 & 2.04 & 44.20 \\
\hline 2014 & 17239.07 & 1364.27 & 54.26 & 90.71 & 1.97 & 43.30 \\
\hline 2015 & 17250.74 & 1371.22 & 55.50 & 90.66 & 2.15 & 41.10 \\
\hline 2016 & 17441.79 & 1378.67 & 56.74 & 90.51 & 2.10 & 40.10 \\
\hline 2017 & 18111.96 & 1386.40 & 57.96 & 89.68 & 2.08 & 40.50 \\
\hline
\end{tabular}

oxidation rate of energy combustion; and 44 and 12 are the molecular weights of $\mathrm{CO}_{2}$ and carbon, respectively.

According to IPCC guidelines for national greenhouse gas inventory [31], carbon dioxide emissions coefficients of various energies are shown in Table 4 . Since electric power is a secondary energy and $70 \%$ of China's electric power is coal power, this paper converts energy consumption volumes of electric power into equivalent standard coal and, then, converts the carbon dioxide emissions of standard coal into those of electric power.

According to statistics data for energy consumptions of the Chinese transportation industry from the International
Energy Agency, as well as the carbon dioxide emissions coefficients of various energies described in Table 4, calculated by means of formula (3), the carbon dioxide emissions volumes of Chinese transportation industry from 1973 to 2017 are, finally, obtained, as shown in Figure 1.

3.2. Prediction and Analysis of Influencing Factors. When using the SVR model to predict carbon dioxide emissions of the Chinese transportation industry, it is generally required to set the future value of the influencing factors reasonably to ensure the accuracy of prediction. However, the error of 
TABLE 4: Carbon dioxide emissions coefficients of transportation and energy.

\begin{tabular}{lccc}
\hline Types of energy & Average low calorific value $\left(V_{i}\right)(\mathrm{kJ} /$ toe $)$ & Carbon oxidation rate $\left(R_{i}\right)(\%)$ & $\mathrm{CO}_{2}$ emission factor $\left(F_{i}\right)(\mathrm{kgCO} / \mathrm{GJ})$ \\
\hline Coal & 20908 & 1 & 94.6 \\
Oil products & 43070 & 1 & 72.35 \\
Biomass energy & 42338 & 1 & 75.18 \\
Natural gas & 38931 & 1 & 56.1 \\
Electric power & - & - & - \\
\hline
\end{tabular}

Note: data source: the Intergovernmental Panel on Climate Change (IPCC) 2006 edition.

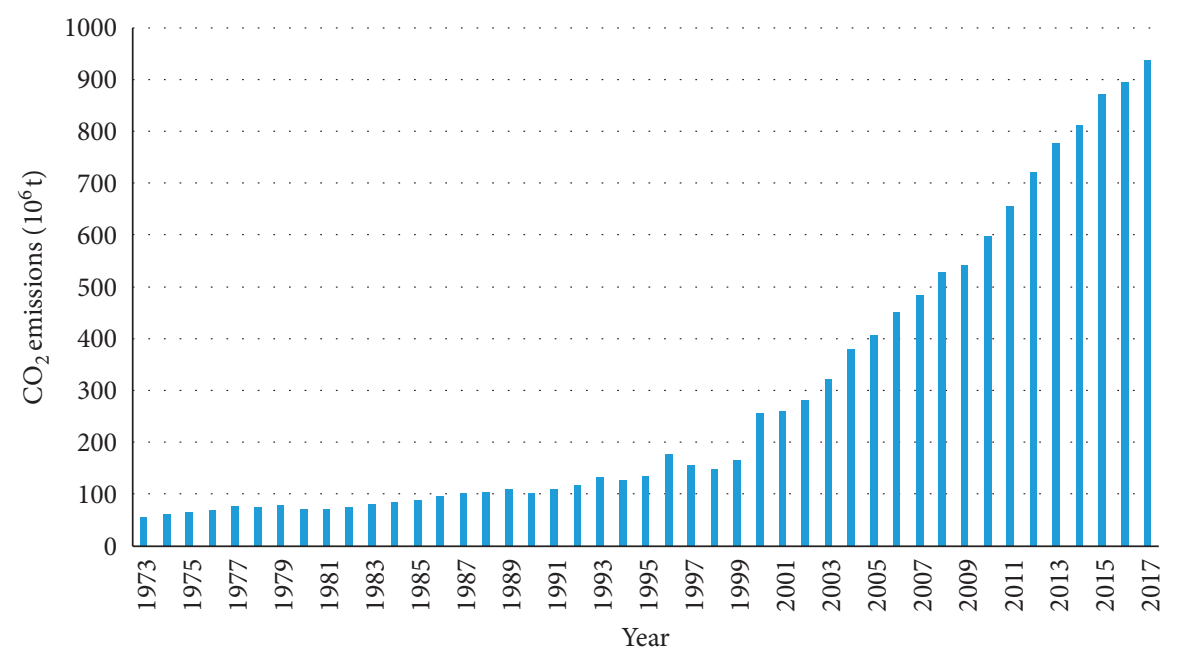

Figure 1: Carbon dioxide emissions from the Chinese transportation industry from 1973 to 2017.

setting the future value of each influencing factor has a little influence on the prediction of the final dependent variable.

3.2.1. Prediction of GDP. In 2015, the research group of the Economic Research Institute of the National Development and Reform Commission released the interim results of the Research on Chinese Development Environment, Development Trend, and Strategic Thinking during the 13th Five-year Plan Period, which concluded that the average growth rate of the Chinese economy was around 6.5\% during the 13th fiveyear plan period. According to the Economic Blue Book released by the Chinese Academy of Social Sciences in 2018, the Chinese economy was expected to grow by about $6.6 \%$ in the year, continuing an overall stable and healthy development trend, and the Chinese GDP growth rate was forecast to be around $6.4 \%$ in $2019,0.2$ percentage points lower than that of the previous year. According to the Chinese Economic Report in 2018, the annual average growth rates of the Chinese economy were predicted to be $6.5 \%$ in 2016-2020 and drop to 5.0\% in 2021-2035. In February 2019, the China Development Research Foundation predicted that the Chinese economic growth rate would be more than 6.0 percent by 2021 and would drop to around 5.0 percent after 2022. Based on the abovementioned predicted results, this paper sets the growth rates of Chinese economical development in 2018-2025, 2026-2030, 2031-2035, 2036-2040, 2041-2045, and 2046-2050 as 6.0\%, 5.5\%, 5.0\%, $4.5 \%, 4.0 \%$, and $3.5 \%$, respectively. The setting value of the growth rate of Chinese GDP in each period of the high- carbon scenario is $0.3 \%$ higher than those of the baseline scenario, while the setting value of the growth rate of Chinese GDP in each period of the low-carbon scenario is $0.3 \%$ lower than those of the baseline scenario.

3.2.2. Population Prediction. According to the report on national population development strategy research released by the Chinese group of national population development strategy research, the total population of China will reach 1.45 billion by 2020, and it is predicted that the total population of China will reach a peak of about 1.5 billion around 2033 [32]. According to the national population development plan (2016-2030) issued by the state council in 2016, the annual natural growth rate during the 12th fiveyear plan period remained at about $5 \%$, and the total population growth in the following 15 years presented an inertia reduce, reaching a peak around 2030. The world population outlook 2019: development summary released by the United Nations in 2019 predicts the population trend of China. The population of China in 2018 was 1.395 billion people. The UN's medium fertility model predicts that China will reduce by about 30 million people by 2050, and the UN's low fertility model predicts that China will reduce by 136 million people by 2050. The Institute of Population and Labor Economics of the Chinese Academy of Social Sciences and the Social Sciences Academic Press jointly published the green book on population and labor: Chinese population and labor issues No. 19, which predicted that the Chinese population would reach a peak of 1.442 billion in 2029, enter a 
continuous negative growth from 2030 , and reduce to 1.364 billion in 2050 [33].

Based on the results predicted above, this paper sets up the change rates of the Chinese population in 2018-2025, 2026-2030, 2031-2035, 2036-2040, 2041-2045, and $2046-2050$ as $0.4 \%, 0.2 \%,-0.2 \%,-0.3 \%,-0.4 \%$, and $-0.5 \%$, respectively, under the set baseline scenarios. The setting value of the change rate of population in each period of the highcarbon scenario increases by $0.1 \%$ compared with those in the baseline scenario, while the setting value of the change rate of population in each period of the low-carbon scenario decreases by $0.1 \%$ compared with those in the baseline scenario.

3.2.3. Prediction of the Urbanization Rate. Changes of the Chinese urbanization rate over the years are shown in Figure 2. According to the 2013 China Human Development Report released by the United Nations Development Program (UNDP), the urbanization rate in China will reach $70 \%$ by 2030 [34]. According to the National New Urbanization Plan (2014-2020) issued by the Chinese State Council in 2014 and the 13th Five-year Plan for National Economic and Social Development in 2016, the Chinese urbanization rate will reach $60 \%$ by 2020 . In 2019, the Chinese Academy of Social Sciences Institute of Urban Development and Environment Research and the Social Sciences Academic Press jointly released the Urban Blue Book: China City Development Report No. 12, which points out that the Chinese urbanization rate reached $59.58 \%$ in 2018. It is about to enter in the late stage of urbanization. By 2050, the Chinese urbanization rate will reach $80 \%$ and the urbanization still has a relatively large development space and potential.

Based on the results predicted above, this paper sets the annual average growth rate of the urbanization rate from 2018 to 2025 as $1.5 \%$, and the urbanization rate will reach $60.61 \%$ by 2020 . The annual average growth rate from 2026 to 2030 will be $1.3 \%$, and the urbanization rate will be $69.65 \%$ by 2030 . The annual growth rates of 2031-2035, 2036-2040, 2041-2045, and 2046-2050 are 1.1\%, 0.9\%, 0.8\%, and 0.7\%, respectively. In the high-carbon scenario, the setting value of the annual average growth rate of urbanization in each period increases by $0.1 \%$ compared with those of the baseline scenario, while in the low-carbon scenario, the setting value of the annual average growth rate of urbanization in each period decreases by $0.1 \%$ compared with those of the baseline scenario.

3.2.4. Prediction of Energy Consumptions Structure. The proportion of fossil energy consumption in the Chinese transportation industry was $100 \%$ in 1973 and $89.68 \%$ in 2017, showing an overall downward trend. The energy strategic action plan (2014-2020), released by the state council in 2014, aims to increase the proportion of nonfossil energy in primary energy consumptions to $15 \%$ and that of natural gas to more than $10 \%$ by 2020 . Similarly, the 13th five-year energy development plan, released by the national development and reform commission in 2016, pointed out that efforts should be made to promote the transformation of energy production and utilization, build a clean, low-carbon, safe, and efficient modern energy supply and demand system, and increase the proportion of nonfossil energy consumption to $15 \%$ by 2020. In 2015, the Chinese government issued the Strengthening Action on Climate Change- Chinese Independent Contribution Rate, which proposed that the proportion of nonfossil energy in primary energy consumption should reach about $20 \%$ by 2030 . In 2018, the China Petroleum Institute of Economics and Technology released the World and Chinese Energy Outlook 2050, which indicated that the proportion of Chinese nonfossil energy will reach about $23 \%$ in 2030, and coal, oil, and nonfossil energy will account for one-third, respectively, by 2050 .

Therefore, according to the abovementioned policy planning and the prediction of relevant institutions, this paper sets, under the baseline scenario, the change rates of energy consumptions structure in 2018-2025, 2026-2030, 2031-2035, 2036-2040, 2041-2045, and $2046-2050$ are, respectively, $-2.0 \%,-1.6 \%,-1.3 \%$, $-1.0 \%,-0.8 \%$, and $-0.6 \%$. In the high-carbon scenario, the setting value of the change rate of energy consumption structure in each period increases by $0.5 \%$ compared with those of the baseline scenario, while the setting value of the change rate of energy consumption structure in each period of the low-carbon scenario decreases by $0.5 \%$ compared with those of the baseline scenario.

3.2.5. Prediction of Energy Intensity. The change trend and annual change rate of energy intensity for the Chinese transportation industry in each year within the research range are shown in Figure 3. From 1973 to 2017, the energy intensity of the Chinese transportation industry witnessed a fluctuant change, and the annual growth rate also fluctuated relatively large. From 1976 to 1990, it showed a relatively large decline; from 1991 to 2003, it changed with fluctuation; in 2003, the energy intensity reached the peak, and since then, the energy intensity fluctuated slowly and had a downward trend.

The Chinese 13th Five-year Plan for National Economic and Social Development in 2016 called for a 15\% reduction in energy intensity during the 13th five-year plan period. According to the existing policies and energy intensity trends, this paper sets that, under the baseline scenario, the change rates of energy intensity in 2018-2025, 2026-2030, 2031-2035, 2036-2040, 2041-2045, and 2046-2050 are $-2.0 \%,-1.8 \%,-1.6 \%,-1.4 \%,-1.2 \%$, and $-1.0 \%$, respectively. The setting value of the change rate of energy intensity in each period of the high-carbon scenario increases by $0.2 \%$ compared with those in the baseline scenario, while the setting value of the change rate of energy intensity in each period in the low-carbon scenario decreases by $0.2 \%$ compared with those in the baseline scenario.

3.2.6. Prediction of the Industrial Structure. The industrial structure in this paper refers to the proportion of the secondary industry in GDP. Figure 4 shows the trend of the 


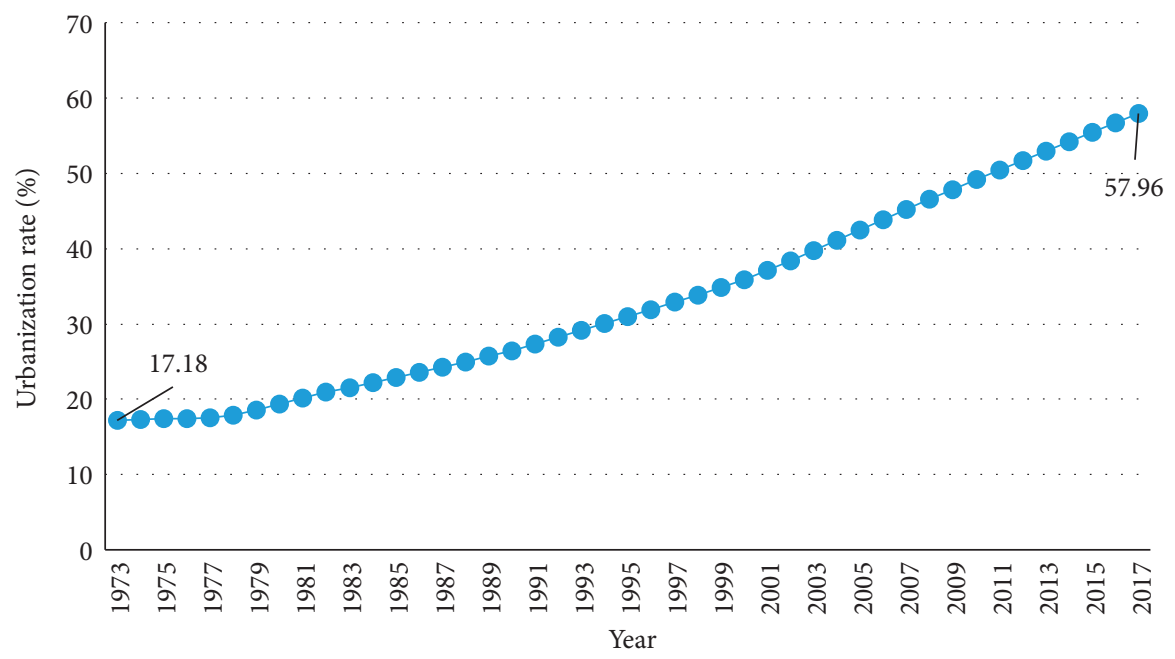

Figure 2: Chinese urbanization rates over the years.

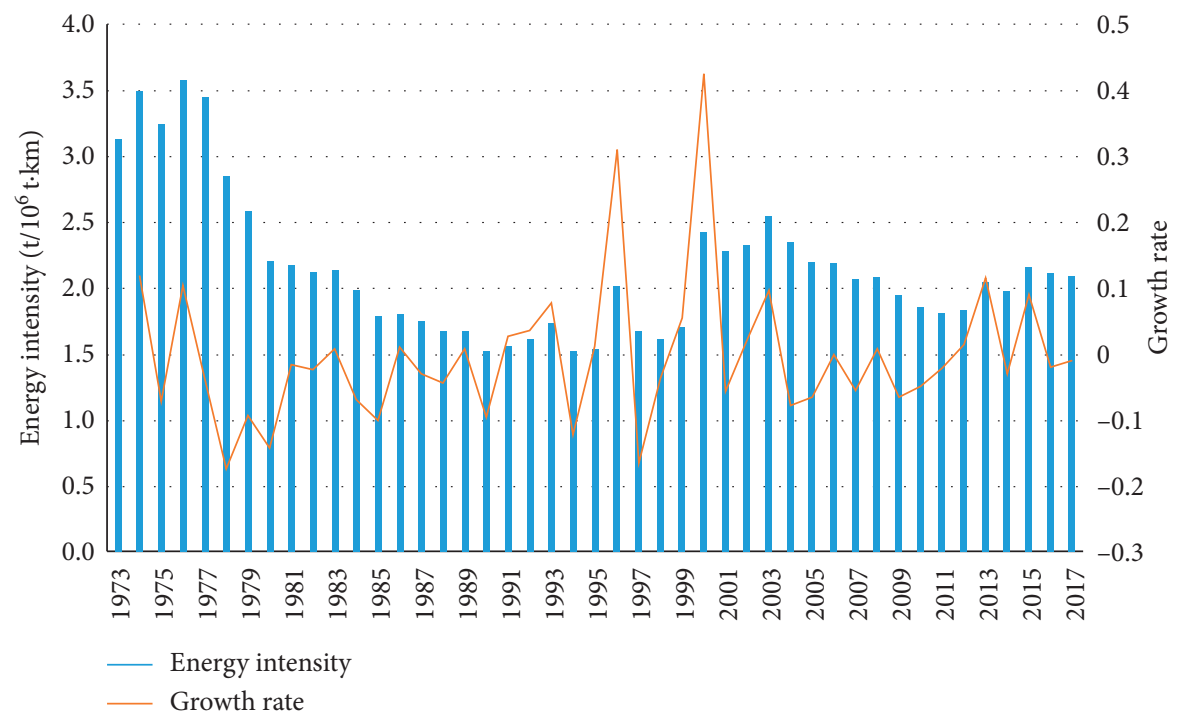

Figure 3: The energy intensity and its growth rate.

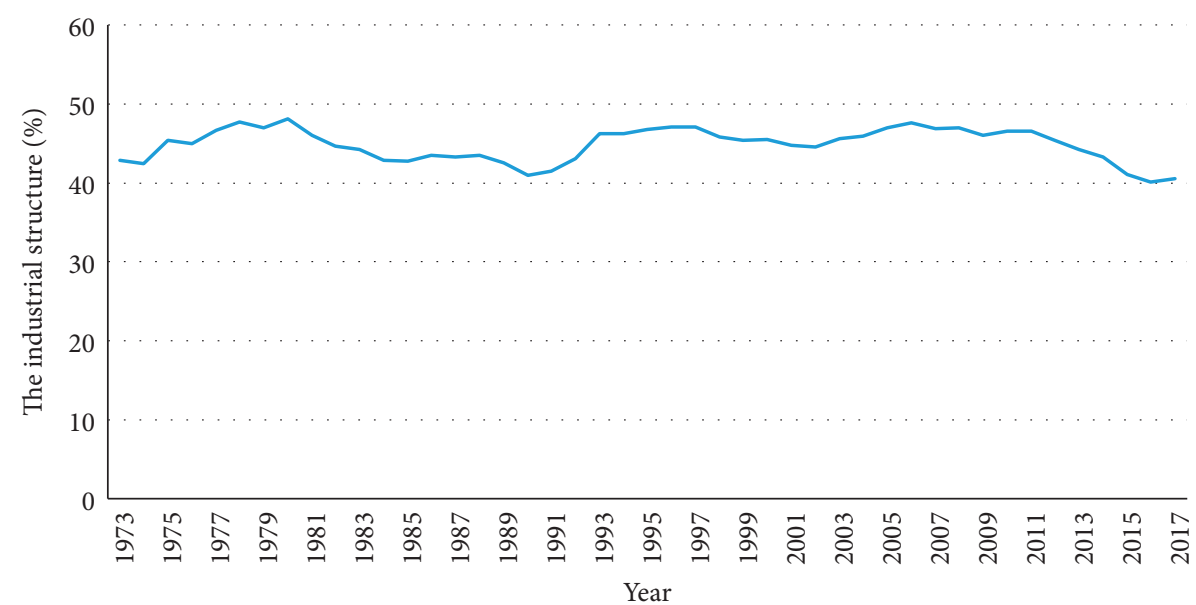

Figure 4: The proportion of secondary industry in Chinese GDP from 1973 to 2017. 
proportion of the secondary industry in GDP in China from 1973 to 2017.

On the whole, the proportion of secondary industry changes relatively gradually, basically maintaining in the range of $40-50 \%$, and the annual average rate of change from 1973 to 2017 is only $-0.13 \%$. After 2011 , the decline trend was obvious, and the annual average rate of change from 2011 to 2017 was $-2.28 \%$. In 2017, the proportion of secondary industry was $40.5 \%$. With the development of Chinese economy and the upgrading and transformation of the industrial structure, the proportion of the secondary industry in China will continue to decline in the future. In 2013, the China 2030 was released by the joint research group of the World Bank and the Development Research Center of the state council. It predicted that, in the absence of major changes in the international situation and no major impact of reform, the proportion of secondary industry in China will decline and reach $34.6 \%$ of GDP in 2030.

At present, the Chinese economy is in a new normal period of "speed change, structure optimization, and motivation transformation," and the trend of accelerating the transformation of the economy from industry domination to service industry domination is more obvious. Taking into account the historical change trend of the proportion of secondary industry in China and the prediction results of relevant institutions, the change rates of the industrial structure in 2018-2025, 2026-2030, 2031-2035, 2036-2040, 2041-2045, and 2046-2050 under the baseline scenario set in this paper are $-1.5 \%,-1.4 \%,-1.3 \%,-1.2 \%,-1.1 \%$, and $-1.0 \%$, respectively. In the high-carbon scenario, the setting value of the change rate of the industrial structure in each period increases by $0.2 \%$ compared with those of the baseline scenario, while in the low-carbon scenario, the setting value of the change rate of the industrial structure in each period decreases by $0.2 \%$ compared with those of the baseline scenario.

3.2.7. Summary of Growth Rates Setting of the Influencing Factors. The growth rate setting of each influencing factor under the three scenarios is shown in Table 5.

\section{Discussion}

4.1. Operation Results of the SVR Model. Firstly, the influence factors of GDP, population, and urbanization rate of carbon dioxide emissions in transportation industry are taken as the input data of the model and the volumes of carbon dioxide emissions as the output data, and then, the data of 37 years from 1973 to 2009 are used as the sample set for simulation and emulation.

Secondly, according to the steps of the nonlinear $\varepsilon$-SVR prediction model, the sample data of the 37 years are normalized and the prediction model is established. When conducting sample training and prediction, the penalty factor $c$ and parameter $g$ of kernel function need to be determined. MATLAB software is used to process relevant data. The initial value of $\varepsilon$ is set at 0.01 , and the value of $c$ and $g$ both range in $\left[2^{-8}, 2^{8}\right]$. After repeated tests, when $c$ is set at 0.5743 and $g$ at
1.0353 , the predicted data of sample set are fitted and regressed with the actual data, and the mean square error (MSE) is only 0.000454 , indicating that the predicted results are relatively satisfactory. Figure 5 is the effect diagram for parameter selection of grid algorithm, and Figure 6 shows the comparison between the training sample and the actual value.

Finally, in order to verify the validity of the established model, the data from 2010 to 2017 are taken as test samples for prediction, the predicted data and actual data are fitted for regression, and the mean square error is 0.088836 . All these indicate that the predicted results are close to the true value of carbon dioxide emissions, that is, the SVR model has an excellent prediction effect on carbon dioxide emissions, and therefore, it can be used as an effective method to predict the carbon dioxide emissions of the Chinese future transportation industry.

4.2. Predicted Results on the Peak Values of Carbon Dioxide Emissions. Three scenarios were predicted by using the established SVR model, and the obtained results are shown in Figure 7 and Table 6. It can be found from the predicted results that, in the baseline scenario, the carbon dioxide emissions of the Chinese transportation industry are still in a growing trend from 2018 to 2040, with a peak of 1365.71 million tons in 2040. The peak value corresponding to the low-carbon scenario is 1115.43 million tons, appearing in 2035. In the high-carbon scenario, the total carbon dioxide emissions are on the rise and peak in 2048, but the carbon dioxide emissions are larger than those of other scenarios, at 1738.18 million tons.

Currently, a few scholars have predicted the peak values of carbon dioxide emissions in the Chinese transportation industry. Chen et al. used the Carbon Kuznets Curve (CKC) as the theoretical model to predict the peak values, and the results showed that Chinese carbon dioxide emissions will reach the peak in 2036. Among them, the peak time of the industrial sector is 2031, that of the construction sector is 2035, that of the transportation sector is 2043, and that of agriculture sector is 2026 [35]. Thus, the peak time of the baseline scenario predicted in this paper is close to the prediction result of Chen et al. In addition, Chinese officials at the world climate conference in Copenhagen predicted that Chinese greenhouse gas emissions will peak between 2030 and 2040. Yuan et al., taking into account the changing trends of Chinese future population, GDP, industrial structure, urbanization, energy intensity and energy consumption, predicted that Chinese carbon dioxide emissions will reach a peak of 9.2 to 9.4 billion t from 2030 to 2035 [36]. Generally speaking, the arrival time of the peak of carbon dioxide emissions in the Chinese transportation industry lags behind the national total peak time, as well as those of the agricultural and industrial sectors. By analyzing the predicted results of the abovementioned literatures, it can be inferred that the predicted results of this paper are reasonable to some extent.

4.3. Sensitivity Analysis. To analyze the effect of individual factor influencing on the carbon dioxide emissions of the Chinese transportation industry, this thesis, based on the 
TABLE 5: Growth rates setting of carbon dioxide emissions' influencing factors in the Chinese transportation industry.

\begin{tabular}{|c|c|c|c|c|c|c|c|}
\hline \multirow[b]{2}{*}{ Scenario } & \multirow[b]{2}{*}{ Year } & \multicolumn{6}{|c|}{ Growth rate setting (\%) } \\
\hline & & GDP & Population & Urbanization rate & Energy consumptions structure & Energy intensity & $\begin{array}{l}\text { Industrial } \\
\text { structure }\end{array}$ \\
\hline \multirow{6}{*}{ High-carbon scenario } & $2018-2025$ & 6.3 & 0.5 & 1.4 & -1.5 & -1.8 & -1.3 \\
\hline & $2025-2030$ & 5.8 & 0.3 & 1.2 & -1.1 & -1.6 & -1.2 \\
\hline & $2031-2035$ & 5.3 & -0.1 & 1.0 & -0.8 & -1.4 & -1.1 \\
\hline & $2036-2040$ & 4.8 & -0.2 & 0.8 & -0.5 & -1.2 & -1.0 \\
\hline & $2041-2045$ & 4.3 & -0.3 & 0.7 & -0.3 & -1.0 & -0.9 \\
\hline & $2046-2050$ & 3.8 & -0.4 & 0.6 & -0.1 & -0.8 & -0.8 \\
\hline \multirow{6}{*}{ Baseline scenario } & $2018-2025$ & 6.0 & 0.4 & 1.5 & -2.0 & -2.0 & -1.5 \\
\hline & $2025-2030$ & 5.5 & 0.2 & 1.3 & -1.6 & -1.8 & -1.4 \\
\hline & $2031-2035$ & 5.0 & -0.2 & 1.1 & -1.3 & -1.6 & -1.3 \\
\hline & $2036-2040$ & 4.5 & -0.3 & 0.9 & -1.0 & -1.4 & -1.2 \\
\hline & $2041-2045$ & 4.0 & -0.4 & 0.8 & -0.8 & -1.2 & -1.1 \\
\hline & $2046-2050$ & 3.5 & -0.5 & 0.7 & -0.6 & -1.0 & -1.0 \\
\hline \multirow{6}{*}{ Low-carbon scenario } & $2018-2025$ & 5.7 & 0.3 & 1.6 & -2.5 & -2.2 & -1.7 \\
\hline & $2025-2030$ & 5.2 & 0.1 & 1.4 & -2.1 & -2.0 & -1.6 \\
\hline & $2031-2035$ & 4.7 & -0.3 & 1.2 & -1.8 & -1.8 & -1.5 \\
\hline & $2036-2040$ & 4.2 & -0.4 & 1.0 & -1.5 & -1.6 & -1.4 \\
\hline & $2041-2045$ & 3.7 & -0.5 & 0.9 & -1.3 & -1.4 & -1.3 \\
\hline & 2046-2050 & 3.2 & -0.6 & 0.8 & -1.1 & -1.2 & -1.2 \\
\hline
\end{tabular}

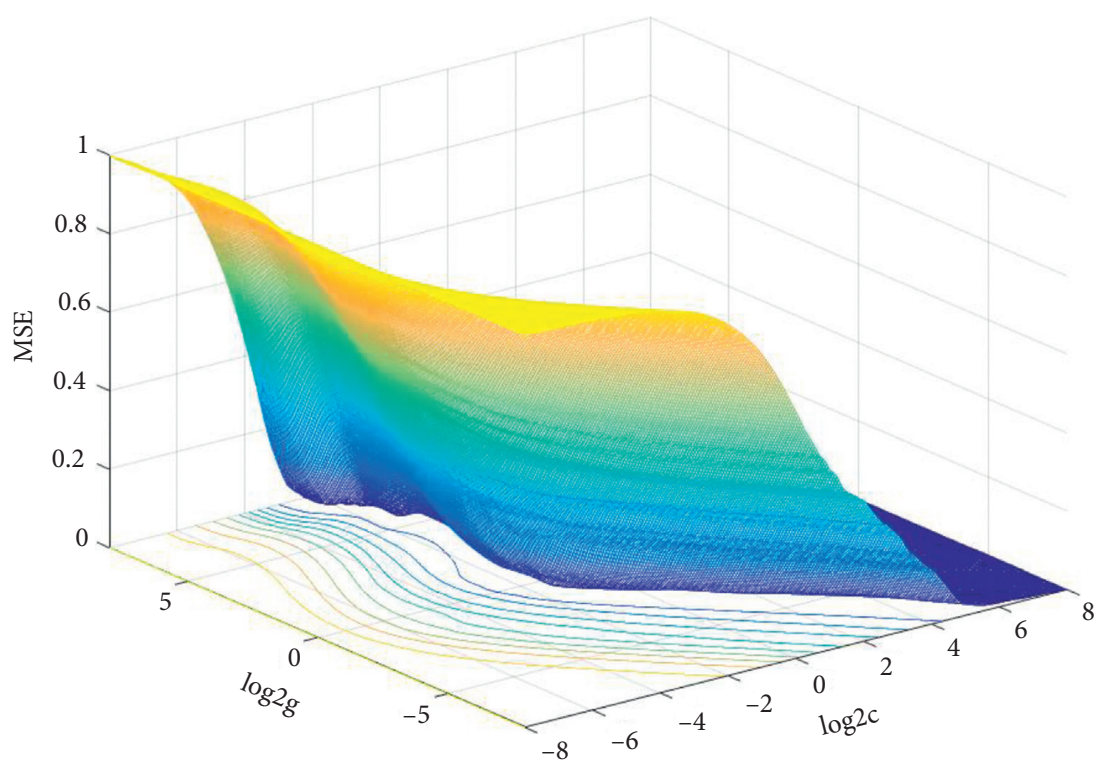

FiguRE 5: The effect diagram for parameter selection of grid algorithm (3D).

baseline scenario, changes a kind of factors affecting the change rate in sequence, namely, on the basis of the baseline rate changes $-10 \%$ and $10 \%$, respectively. When the change rates of other factors are the values of rate settings of the baseline scenario, it quantitatively analyzes of the factors that affect the carbon dioxide emissions of the Chinese transportation industry. The results are shown in Table 7 .

Overall, GDP, population, and other factors have a certain influence on carbon dioxide emissions. Among all the influencing factors, the change of energy consumption structure has the greatest influence on carbon dioxide emissions. With the rate of energy consumption structure decreasing by $10 \%$, the peak value of carbon dioxide emissions decreases by $4.13 \%$ compared with that of the baseline scenario, and the total carbon dioxide emissions will decrease by $3.39 \%$ from 2018 to 2050 . Population is next. With the change rates of population falling by $10 \%$, the peak value of carbon dioxide emissions falls by $4.07 \%$, and the total carbon dioxide emissions will fall by $3.32 \%$ between 2018 and 2050. Among them, GDP and the urbanization rate have less influence on carbon dioxide emissions. The change rate of GDP reduces by $10 \%$, and the total carbon dioxide emissions will reduce by $2.37 \%$ from 2018 to 2050 . The change rate of urbanization rate reduces 


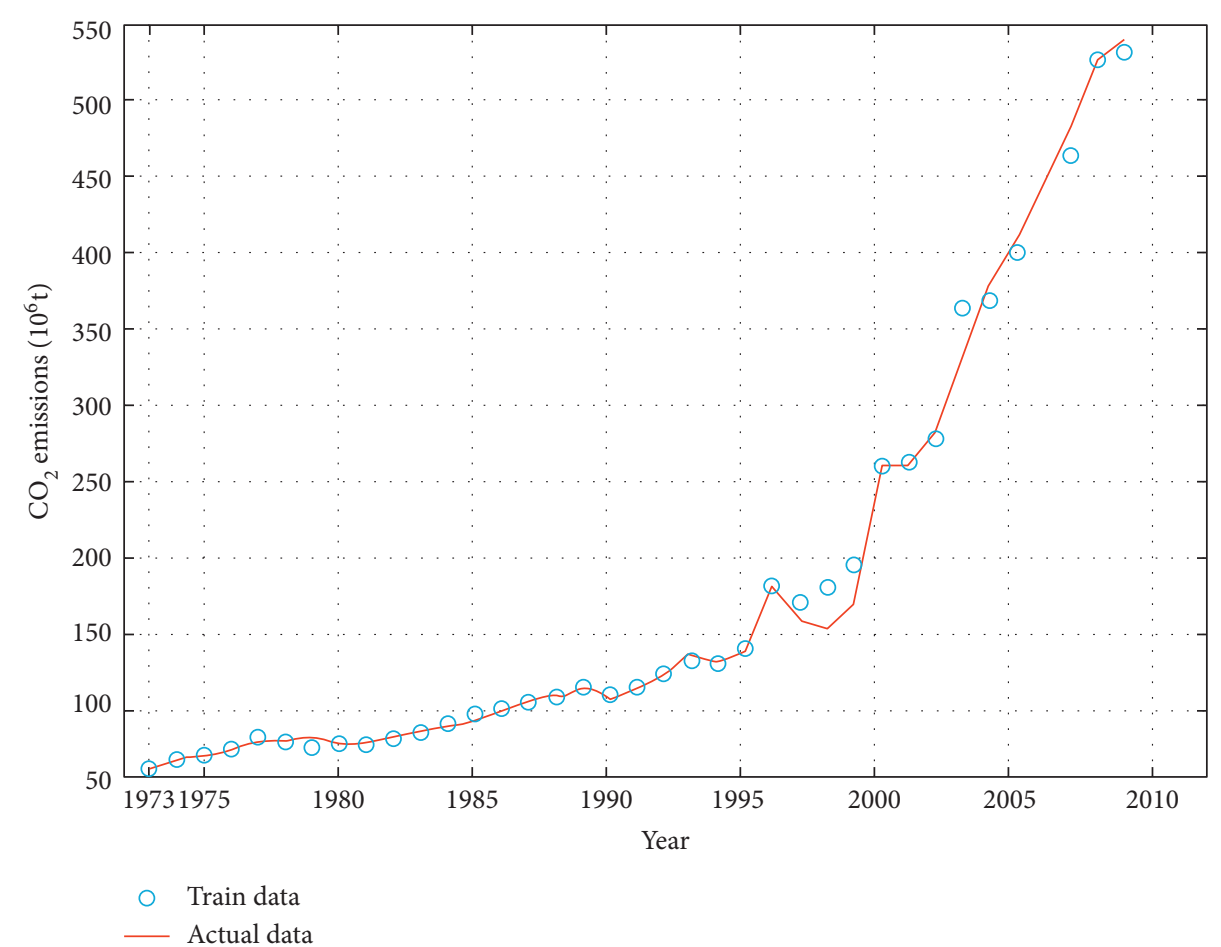

FIgURE 6: Comparison of the predicted value of the training sample with the actual value.

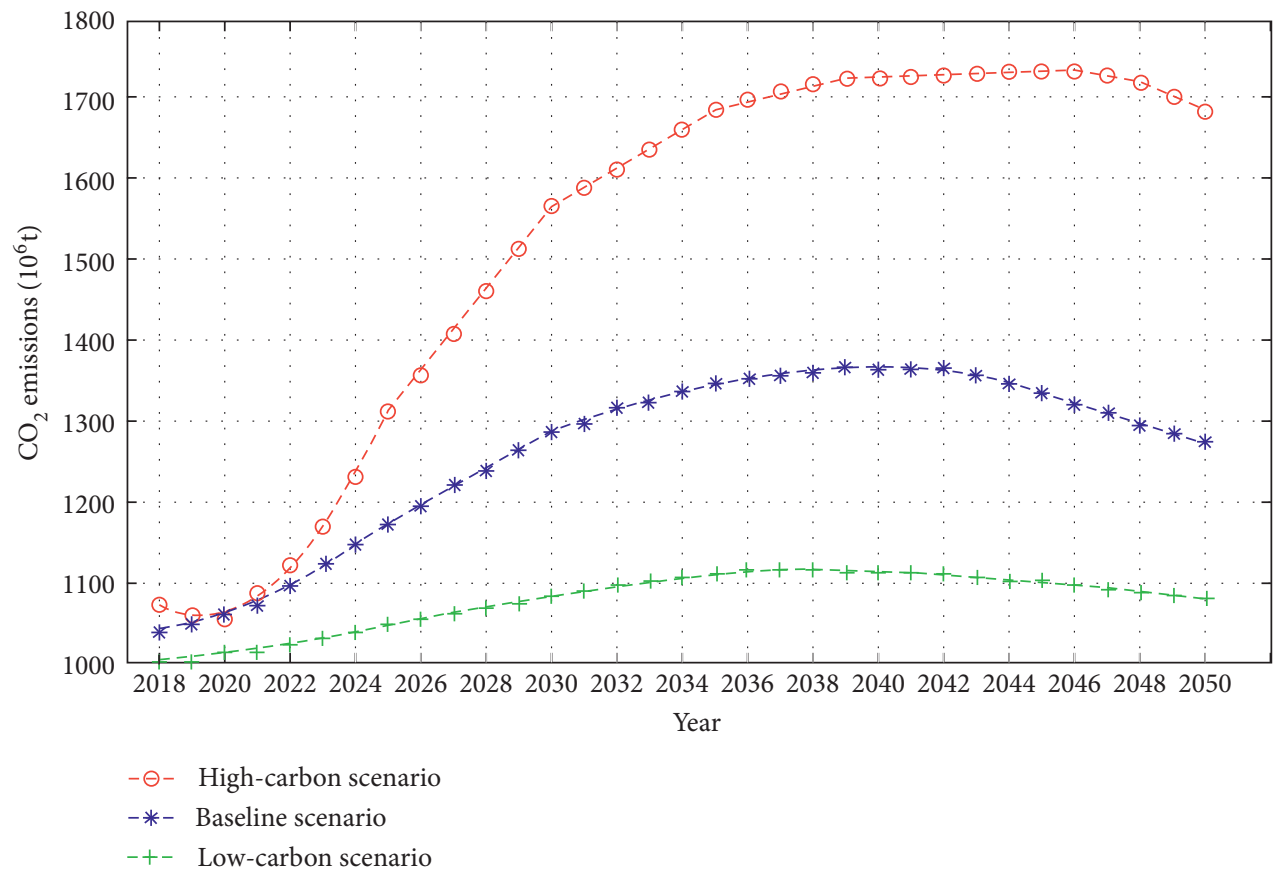

FIgURE 7: The trend of prediction results of carbon dioxide emissions under three scenarios.

TABLE 6: Prediction on peak values of different scenarios. 
TABLE 7: Carbon dioxide emissions of each factor at different change rates.

\begin{tabular}{|c|c|c|c|c|c|}
\hline Factor & $\begin{array}{l}\text { Change rate } \\
(\%)\end{array}$ & $\begin{array}{l}\text { Peak value } \\
\quad\left(10^{6} \mathrm{t}\right)\end{array}$ & $\begin{array}{l}\text { Change of the peak } \\
\text { value }(\%)\end{array}$ & $\begin{array}{l}\text { Total carbon dioxide emissions from } \\
2018 \text { to } 2050\left(10^{6} \mathrm{t}\right)\end{array}$ & $\begin{array}{c}\text { Change of } \\
\text { total } \\
\text { volume (\%) }\end{array}$ \\
\hline \multirow{2}{*}{ GDP } & -10 & 1358.13 & -0.55 & 40610.82 & -2.37 \\
\hline & 10 & 1420.17 & 3.99 & 42988.74 & 3.34 \\
\hline \multirow{2}{*}{ Population } & -10 & 1310.10 & -4.07 & 40216.32 & -3.32 \\
\hline & 10 & 1424.80 & 4.33 & 43066.51 & 3.53 \\
\hline \multirow{2}{*}{ Urbanization rate } & -10 & 1311.01 & -4.00 & 40240.50 & -3.26 \\
\hline & 10 & 1423.63 & 4.24 & 43034.93 & 3.45 \\
\hline \multirow{2}{*}{$\begin{array}{l}\text { Energy consumptions } \\
\text { structure }\end{array}$} & -10 & 1309.34 & -4.13 & 40189.08 & -3.39 \\
\hline & 10 & 1425.78 & 4.40 & 43096.09 & 3.60 \\
\hline \multirow{2}{*}{ Energy intensity } & -10 & 1310.57 & -4.04 & 40226.69 & -3.30 \\
\hline & 10 & 1424.21 & 4.28 & 43052.69 & 3.50 \\
\hline \multirow{2}{*}{ Industrial structure } & -10 & 1310.88 & -4.01 & 40228.06 & -3.31 \\
\hline & 10 & 1423.81 & 4.25 & 43051.13 & 3.49 \\
\hline
\end{tabular}

by $10 \%$, and the total carbon dioxide emissions from 2018 to 2050 will reduce by $3.26 \%$.

From Table 7 and the abovementioned analysis, it can be seen that, in order to reduce the carbon dioxide emissions of the transportation industry, it is necessary to reasonably control all of the influencing factors. First, we reduce the energy consumption structure and energy intensity of the transportation industry, improve the efficiency of clean energy, and actively promote the use of new energy and clean energy vehicles and ships. Second, we change the pattern of economic growth, appropriately reduce the speed of economic development, and strive to achieve coordinated development between economic growth and environmental protection. At the same time, we need to optimize the industrial structure, move the industry toward the middle and high end, achieve highquality development, and reduce the demand for transportation, thereby reducing the carbon dioxide emissions. Although the change of urbanization rate has a relatively small influence on the carbon dioxide emissions of the transportation industry, urbanization has changed people's lifestyle and their demands for energy are increasing. China is in the stage of urbanization, with the population moving from rural areas to cities and towns, and the change of people's production and lifestyle affects the change of carbon dioxide emissions. Therefore, the rational development of urbanization also has an important influence on the reduction of carbon dioxide emissions.

\section{Conclusions and Suggestions}

5.1. Conclusions. Taking the Chinese transportation industry as the research object, this paper selects six major factors that affect the carbon dioxide emissions of the Chinese transportation industry, GDP, population, urbanization rate, energy consumption structure, energy intensity, and industrial structure, and establishes the prediction model for the peak of carbon dioxide emissions based on SVR. The mean square error of the prediction model is 0.000454 , indicating a relatively high degree of coincidence of the model. The predicted results show that, under the low-carbon scenario, the carbon dioxide emissions of the Chinese transportation industry will peak at 1115.43 million tons in 2036. Under the baseline scenario, it will reach a peak of 1365.71 million tons in 2040. In the highcarbon scenario, the peak will occur in 2046 and the carbon dioxide emissions will be 1738.18 million tons. Finally, the influence of a single factor on the carbon dioxide emissions of the Chinese transportation industry is analyzed, which indicates that the change of each factor will have a certain influence on the peak of carbon dioxide emissions and the total carbon dioxide emissions from 2018 to 2050 .

5.2. Suggestions. Since the peak time and total carbon dioxide emissions of the Chinese transportation industry vary greatly under different scenarios, major factors affecting the growth of carbon dioxide emissions must be controlled in order to promote the early peak time of the Chinese transportation industry. First, the pattern of economic growth is changed and the speed of economic development is appropriately reduced. The results of this paper show that the slowdown of economic growth is one of the main factors contributing to reducing the peak and total carbon dioxide emissions of the Chinese transportation industry. Therefore, China should gradually change the mode of economic growth, appropriately reduce the speed of economic development, and strive to achieve the coordinated developments of economic growth and environmental protection. Second, the energy intensity of the transportation industry is reduced and the utilization rate of clean energy is improved. We speed up the optimization of the structure of the transportation industry, reduce the volumes of bulk goods transported by road, increase the volumes of bulk goods transported by rail and waterways, substantially increase the volumes of multiple modes of combined transportation by port, railway, and container transportation, and reduce energy intensity. We actively promote the use of new and clean energy vehicles and ships and control $\mathrm{CO}_{2}$ emissions from the transportation industry. Third, we improve the industrial structure, actively promote the optimization and upgrading of the industrial structure, develop strategic emerging industries and modern service industries, and move the industry to the medium-high end and achieve high-quality development, so as to reduce the demand for transportation and reduce carbon 
dioxide emissions. Fourth, we reasonably control the traffic carbon dioxide emissions caused by the increase of the urbanization rate. We encourage residents to travel in a green way, gradually build a green travel structure with public transportation as the main part and walking and cycling as the auxiliary part, and reduce the frequency of car use.

\section{Data Availability}

In this paper, population and urbanization rate come from World Development Indicators (WDI), and the energy consumption structure comes from the International Energy Agency (IEA). Here is the percentage of fossil energy consumption in transportation industry accounting for the total energy consumptions. Total energy consumption in the Chinese transportation sector comes from the website of IEA. The rest of the data come from the comprehensive and publicly published Chinese Statistical Yearbook of past years. The sample interval is from 1973 to 2017.

\section{Conflicts of Interest}

The authors declare no conflicts of interest.

\section{Authors' Contributions}

Changzheng Zhu and Meng Wang conceived the study, wrote original draft, and contributed to all aspects of this work. Wenbo $\mathrm{Du}$ analyzed the data and gave some useful suggestions to this work.

\section{Acknowledgments}

The authors thank Dawei Gao for his help in participation in data collection and Lijiao Qin for her help in the English editing. This research was funded by the National Social Science Foundation in China (Grant no. 19BJY175), Shaanxi Natural Science Foundation project (Grant no. 2019JQ-533), Xi'an Science and Technology Plan (Grant no. 2019111913RKX003SF007-10), and Innovation fund for graduate students of $\mathrm{Xi}$ an University of Posts and Telecommunications (Grant no. CXJJWY2018096).

\section{References}

[1] L. Shipper, L. Scholl, and L. Price, "Energy use and carbon emissions from freight in 10 industrialized countries: an analysis of trends from 1973 to 1992," Transportation Research Part D: Transport and Environment, vol. 2, pp. 57-76, 1997.

[2] G. R. Timilsina and A. Shrestha, "Transport sector $\mathrm{CO}_{2}$ emissions growth in Asia: underlying factors and policy options," Energy Policy, vol. 37, no. 11, pp. 4523-4539, 2009.

[3] G. R. Timilsina and A. Shrestha, "Factors affecting transport sector $\mathrm{CO}_{2}$ emissions growth in Latin American and Caribbean countries: an LMDI decomposition analysis," International Journal of Energy Research, vol. 33, no. 4, pp. 396-414, 2009.

[4] B. Talbi, " $\mathrm{CO}_{2}$ emissions reduction in road transport sector in Tunisia," Renewable and Sustainable Energy Reviews, vol. 69, pp. 232-238, 2017.
[5] C. Zhu and D. Gao, "A research on the factors influencing carbon emission of transportation industry in "the belt and road initiative" countries based on Panel data," Energies, vol. 12, no. 12, p. 2405, 2019.

[6] Y. Liang, D. Niu, H. Wang, and Y. Li, "Factors affecting transportation sector $\mathrm{CO}_{2}$ emissions growth in China: an LMDI decomposition analysis," Sustainability, vol. 9, no. 10, p. 1730, 2017.

[7] Y. Wang, Y. Zhou, L. Zhu, F. Zhang, and Y. Zhang, "Influencing factors and decoupling elasticity of China's transportation carbon emissions," Energies, vol. 11, no. 5, p. 1157, 2018.

[8] Q. Du, Q. Su, Q. Yang, X. Y. Feng, and J. Yang, "Path analysis method of driving factors of carbon emissions for Chinese transportation industry," Journal of Traffic and Transportation Engineering, vol. 17, pp. 143-150, 2017.

[9] Y. Li, "Analysis of the influencing factors of carbon emission from Anhui Transportation Industry based on LMDI," Environmental Protection, vol. 5, pp. 5-8, 2019.

[10] R. J. Zhang, H. Z. Dong, Y. G. Han, and X. Li, “The spatial correlation analysis of influence factors on carbon emissions from the energy consumption," Journal of Shandong University of Science and Technology, vol. 34, pp. 33-39, 2020.

[11] A. Zhou and K. Y. Wu, "Driving factors analysis of traffic carbon emissions in Shanghai," Journal of Hefei University of Technology (Natural Science), vol. 43, pp. 264-269, 2020.

[12] H. Li, Y. Lu, J. Zhang, and T. Wang, "Trends in road freight transportation carbon dioxide emissions and policies in China," Energy Policy, vol. 57, pp. 99-106, 2013.

[13] B. Xu and B. Lin, "Carbon dioxide emissions reduction in China's transport sector: a dynamic VAR (vector autoregression) approach," Energy, vol. 83, pp. 486-495, 2015.

[14] L. Wu, S. Kaneko, and S. Matsuoka, "Driving forces behind the stagnancy of China's energy-related $\mathrm{CO}_{2}$ emissions from 1996 to 1999: the relative importance of structural change, intensity change and scale change," Energy Policy, vol. 33, no. 3, pp. 319-335, 2005.

[15] Y. E. Zhu, L. F. Li, S. S. He, H. Li, and Y. Wang, "Peak year prediction of Shanxi Province's carbon emissions based on IPAT modeling and scenario analysis," Resources Science, vol. 38, pp. 2316-2325, 2016.

[16] S. N. Qu and C. X. Guo, "Forecast of China's carbon emissions based on STIRPAT model," China Population Resources and Environment, vol. 20, pp. 10-15, 2010.

[17] Y. Z. Zhu, "Analyses on energy development and carbon exhaustion according to circumstances in future China's communications and transportation," China Industrial Economics, vol. 12, pp. 30-35, 2001.

[18] Q. Yang, R. H. Zhu, and X. Q. Zhao, "Calculation decoupling analysis and scenario prediction of carbon emissions of transportation in China," Journal of Chang'an University, vol. 34, pp. 77-83, 2014.

[19] J. Z. Zhang, X. C. Wang, Q. L. Tai, R. F. Xie, and Z. B. Chen, "Forecasting of energy demands and carbon emission of transportation in Hainan province," Natural Science Journal of Hainan University, vol. 35, pp. 164-170, 2017.

[20] P. R. Ehrlich and J. P. Holdren, "Critique," Bulletin of the Atomic Scientists, vol. 28, no. 5, pp. 16-27, 1972.

[21] T. Dietz and E. A. Rosa, "Rethinking the environmental impacts of population, affluence and Technology," Human Ecology Review, vol. 1, pp. 277-300, 1994.

[22] A. U. Gazi, A. Khorshed, and G. Jeff, "Ecological footprint and regional sustainability: a review of methodologies and results," in Proceedings of the 37th Annual Conference of the 
Australia and New Zealand Regional Science Association International (ANZRSAI 2013), Hervey Bay, Australia, December 2013.

[23] S. F. Lin, S. Y. Wang, D. Marinova, and D. T. Zhao, "Improvement and application of STIRPAT model," Statistics \& Decisions, vol. 34, pp. 32-34, 2018.

[24] Z. H. Chen, X. Q. Ye, and P. Huang, "Estimating carbon dioxide $\left(\mathrm{CO}_{2}\right)$ emissions from reservoirs using artificial neural networks," Water, vol. 10, p. 26, 2018.

[25] Y. F. Lin, H. M. Deng, and X. Y. Shi, "Application of BP neural network based on newly improved particle swarm optimization algorithm in in fitting nonlinear function," Computer Science, vol. S2, pp. 51-54, 2017.

[26] J. Cai and X. Ma, "Carbon emission prediction model of agroforestry ecosystem based on support vector regression machine," Applied Ecology and Environmental Research, vol. 3, pp. 6397-6413, 2019.

[27] L. Chen, J. H. Wang, T. He, Z. H. Zhou, Q. R. Li, and W. W. Yang, "Forecast study of regional transportation carbon emissions based on SVR," Journal of Transportation Systems Engineering and Information Technology, vol. 18, pp. 13-19, 2018.

[28] J. K. Song, "China's carbon emissions prediction model based on support vector regression," Journal of China University of Petroleum, vol. 36, pp. 182-187, 2012.

[29] L. M. Xue, X. Z. Zhang, B. K. Liu, and Y. G. Hu, "SVR-based prediction of carbon emissions from energy consumption in Hebei Province," Coal Engineering, vol. 49, pp. 165-168, 2017.

[30] B. R. Li, Economic Forecast Theory, Method and Application, Economy \& Management Publishing House, Beijing, China, 2003.

[31] Intergovernmental Panel on Climate Change (IPCC), IPCC Guidelines for National Greenhouse Gas Inventories 2006 Volume 2 Energy; Intergovernmental Panel on Climate Change, Kanagawa, Japan, 2007.

[32] Z. X. Feng and A. J. Wang, "Comparative study of China regional carbon peak-based on national data and Shaanxi province," Journal of Xi'an Jiaotong University, vol. 36, pp. 96-104, 2016.

[33] C. W. Zhang, Green Paper on Population and Labor: China's Population and Labor Problem Report No. 19, Social Sciences Academic Press, Beijing, China, 1st edition, 2018.

[34] The United Nations Development Programme (UNDP), China National Human Development Report 2013, Sustainable and Liveable Cities, Toward Ecological Civilization, Beijing, China, 2013.

[35] X. Chen, C. Y. Shuai, Y. Wu, and Y. Zhang, "Analysis on the carbon emission peaks of China's industrial, building, transport, and agricultural sectors," Science of the Total Environment, vol. 709, 2020.

[36] J. Yuan, Y. Xu, Z. Hu, C. Zhao, M. Xiong, and J. Guo, "Peak energy consumption and $\mathrm{CO}_{2}$ emissions in China," Energy Policy, vol. 68, pp. 508-523, 2014. 